\title{
Erosão Hídrica e Perda de Carbono O rgânico em Diferentes Tipos de Cobertura do Solo no Semi-Árido, em Condições de Chuva Simulada
}

\author{
Thais Emanuelle Monteiro dos Santos, Abelardo Antônio de Assunção Montenegro \\ Valdemir de Paula e Silva Junior \\ Universidade Federal Rural de Pernambu co- UFRPE \\ thaisemanuelle@hotmail.com, monte@hotlink.com, depaulajr22@yahoo.com.br
}

Suzana Maria Gico Lima Montenegro

Universidade Federal de Pernambuco- UFPE

suzanam@ufpe.br

Recebido: 09/04/07 -revisado: 19/12/07 -aceito: 26/05/08

RESUM 0

Considerando a baixa disponibilidade de recursos hídricos da região semi-árida, e a deficiên cia de manejo hidroagrícola nesta região, objetivou-se avaliar o desempenho de técnicas de con servação de água e solo em bacia representativa do semi-árido de Pernambuco. 0 estudo foi desenvolvido na Bacia do Riacho M imoso, on de se estimaram as perdas de solo, água e de carbono orgânico no sedimento transportado, considerando-se duas intensidades de chuva simulada, 60 e 120 $\mathrm{mm} \mathrm{h}^{-1}$, com duração de 80 minutos. 0 experimento foi conduzido em um N eossolo Flúvico, com declividade de 0,061 $\mathrm{m} \mathrm{m}^{-1}$. Os tratamentos, estabelecidos em parcelas de erosão com dimen sões de $3 \times 1 \mathrm{~m}$, foram: feijão cultivado em nível (N) associado a fileiras de pedra entre as fileiras do feijão; fejjão cultivado morro abaixo (M A); feijão cultivado em nível, com cobertu ra morta (CM ), ten do sido utilizada palha de feijão; solo descoberto (D), e solo com cobertu ra vegetal nativa (caatinga) (CN). A cultura do feijoeiro (Phaseolus vulgaris L.) estava na fase inicial de crescimento, a qual representa uma fase crítica, em termos de índice de cobertura foliar do solo. $0 \mathrm{~s}$ resultados demon straram que a con dição de cobertura natural foi a que ofere ceu a maior proteção ao solo, associada a uma perda de solo, de $4,01 \times 10^{-3} \mathrm{~kg} \mathrm{~m}^{-2}$ e de $6,8 \times 10^{-2} \mathrm{~kg} \mathrm{~m}^{-2}$, para as inten sidades de 60 e $120 \mathrm{~mm} \mathrm{~h}^{-1}$, respectivamente; sendo a cobertura morta a que mais se aproximou desta condição. 0 aumento da intensidade de precipitação aplicada resultou no aumento das perdas de solo e água, com maiores perdas na segu inte ordem: solo descoberto, morro abaixo e em nível. As perdas de carbon o orgânico foram significativamente maiores para as condições de manejo não conservacionista do solo.

Palavras-chave: práticas conservacion istas de solo; perdas de solo, sedimen to; simulador de chuva

INTRODUÇÃO

A região semi-árida do Nordeste apresenta limitada disponibilidade de recursos hídricos, devido a dois fatores preponderantes: solos rasos, com baixa capacidade de retenção de água, e regime pluviométrico irregular, com chuvas mal distribuídas temporal e espacialmente. A produtividade média das atividades agropecuárias nessa região é muito baixa, chegando a níveis baixíssimos em períodos de seca (Padilha, 2000).

Nessa região, no período chuvoso, pratica-se a agricultura de sequeiro, principalmente 0 cultivo de feijão e milho. 0 feijoeiro ocupa posição de destaque no Brasil, não apenas pelo volume de grãos produzidos, mas também pela importância dessa leguminosa na alimentação humana. Segundo Soratto et al. (2005), o feijão é a principal fonte de proteína da maioria da população brasileira, o que tem proporcionado crescente interesse no estudo de técnicas que conduzam a um aumento da produtividade e da qualidade dos seus grãos. Porém, o cultivo dessa leguminosa na região semi-árida, em sua maioria, ainda é realizado sem a adoção de práticas conservacionistas adequadas para a proteção dos solos, os quais apresentam alta susceptibilidade à erosão.

Dentre os tipos de degradação dos solos, a erosão hídrica é a que mais tem afetado a sua capacidade produtiva, facilitada e acelerada pela utilização de práticas inadequadas de manejo agrícola (Carvalho, et al., 2002). Bertoni \& Lombardi Neto (1999) comentam que os sistemas de preparo e ma- 
Erosão Hídrica e Perda de Carbono Orgânico em Diferentes Tipos de Cobertura do Solo no Semi-Árido, em Condições de Chuva Simulada

nejo do solo devem manter a maior cobertura possível da superfície, propiciar maior capacidade de infiltração e assegurar a máxima rugosidade da superfície.

Dentre as práticas conservacionistas, a eficiência da cobertura morta tem sido avaliada em diversas pesquisas de erosão, possibilitando redução das perdas de solo entre 70 e $90 \%$ e incrementos significativos de umidade (Santos et al., 2000; CarvaIho et al., 2002; Silva, 2001). Silveira et al. (2000) avaliaram as perdas de solo e água em parcelas experimentais de $3 \times 1 \mathrm{~m}$, sob condições de chuva simulada com intensidade de $157,8 \mathrm{~mm} \mathrm{~h}^{-1}$, no Campus da Universidade Federal de Lavras, Minas Gerais. Foram aplicados resíduos culturais de milho em diferentes percentagens, verificando-se que a cobertura morta utilizada reduziu acentuadamente as perdas de solo de $74,13 \mathrm{~kg} \mathrm{ha}^{-1}$ (solo descoberto) para 9,08 $\mathrm{kg} \mathrm{ha}^{-1}$, na condição de $60,9 \%$ de cobertura vegetal.

No mesmo sentido, Cassol \& Lima (2003) encontraram taxas de perdas de solo reduzidas em torno de $90 \%$ pelo sistema de plantio direto em relação ao solo descoberto e ao preparo convencional com incorporação de resíduos na cultura da aveia, numa parcela com $16 \%$ de declive, em um Argissolo Vermelho na região de Porto Alegre, sob condições de chuva simulada, e com intensidade de $60 \mathrm{~mm} \mathrm{~h}^{-1}$, durante 70 minutos.

O uso do plantio em nível em substituição ao morro abaixo, é outro exemplo de prática conservacionista que tem-se mostrado eficiente no controle das perdas por erosão hídrica, como constataram Albuquerque et al. (2002). Estes autores, estudando perdas de solo e água em parcelas de erosão com $4 \%$ de declive, em região semi-árida, cultivadas com palma forrageira, em solo classificado como Luvissolo Crômico Órtico vertissólico, verificaram que o cultivo em nível em relação àquele em desnível reduziu as perdas de solo e água em 53,4 e 20\%, respectivamente. Ainda, esses autores observaram a relevância da caatinga nativa, reduzindo em torno de $99 \%$ as perdas de solo em relação à parcela descoberta.

Além de elevadas perdas de solo e água, a erosão hídrica também é responsável pelo empobrecimento dos solos e redução da produtividade da maioria das culturas. Bertol et al. (2004) verificaram baixas perdas de carbono, no sedimento transportado, no tratamento com semeadura direta sob condições de chuva simulada com intensidade de $64 \mathrm{~mm}$ $\mathrm{h}^{-1}$, no Planalto Sul Catarinense. Por sua vez CarvaIho et al. (2007) encontraram maiores perdas de carbono, no sedimento transportado, nas condições onde se manteve maior eficiência da proteção do solo, para a cultura do cafeeiro, quando comparado aos sistemas onde houve exposição do solo; em um Latossolo Vermelho distoférrico típico, com $12 \%$ de declividade, localizado na região de Lavras (MG).

Padilha (2000) propôs a utilização de microbarramentos em pedra nas encostas para conservação de água e solo, de modo a reduzir a velocidade do escoamento superficial, contendo a erosão laminar, permitindo assim a formação de áreas com solos agricultáveis e armazenando água no subsolo. Este projeto, segundo o autor, tem obtido resultados significativos no semi-árido pernambucano, onde se tem mostrado eficiente na conservação dos solos e recuperação progressiva do meio ambiente degradado, e na manutenção da matéria orgânica no solo.

A erosão é uma das principais causas de diminuição da fertilidade do solo, especialmente na fase de crescimento de uma cultura (fase crítica em termos de cobertura do solo), quando as perdas de água, solo e nutrientes são, via de regra, mais elevadas. Assim, a avaliação desse processo em tal fase é essencial para o planejamento de práticas conservacionistas eficiente. Com efeito, Vieira et al. (1978) avaliaram as perdas de solo durante todo o ciclo da cultura da soja, sob chuva simulada com intensidades de 60 e $120 \mathrm{~mm} \mathrm{~h}^{-1}$, em um solo Nitossolo Vermelho, com $6 \%$ de declive, pertencente à Unidade de Mapeamento São Jerônimo, RS. Os autores verificaram que, ao final da série de chuvas, cerca de $90 \%$ das perdas totais de solo durante todo o ciclo da cultura, eram referentes ao período entre a semeadura até cerca de $25 \%$ do desenvolvimento vegetativo da soja.

Nesse estudo, objetivou-se avaliar o desempenho de técnicas de conservação de água e solo no controle de taxas erosivas e perdas de carbono orgânico no sedimento transportado, sob condições de chuva simulada, em solo cultivado com feijão (Phaseolus vulgaris L.), em fase inicial de crescimento, no semi-árido.

\section{MATERIAL E MÉTODOS}

Avaliação das características hidráulicas do simulador de chuvas

O simulador de chuvas foi desenvolvido para atuar em parcelas experimentais no campo, é de fácil locomoção, sendo formado por uma armação retangular apoiada sob quatro pés tubulares de aço removíveis. Possui um motor com sistema eletrônico o qual realiza movimentos oscilantes temporizados. 
O dispositivo funciona com um bico aspersor, o qual se localiza no centro da armação a $3 \mathrm{~m}$ de altura do solo, recobrindo uma parcela de $1 \mathrm{~m}$ de largura por $3 \mathrm{~m}$ de comprimento, altura esta capaz de gerar energia cinética e diâmetro de gotas de chuva semeIhantes às da chuva natural (Meyer $\& \mathrm{Harmon}$, 1979).

Foram calibrados dois bicos Veejet "80-100" e "80-150", da Spraying Systems Company, de São Bernardo do Campo, SP. O dispositivo foi instalado no Laboratório de Máquinas e Implementos Agrícolas da UFRPE, para realização dos testes de calibração. Sob o simulador foram dispostos 21 pluviômetros nivelados entre si, sendo os pluviômetros de 6,8 $\mathrm{cm}$ de diâmetro e $13 \mathrm{~cm}$ de altura, ocupando uma área de formato retangular, com 1,0 m de largura e $3 \mathrm{~m}$ de comprimento, e espaçamento entre os pluviômetros de 0,5 m. Manômetro e registro permitiam ajuste da pressão desejada.

O coeficiente de uniformidade de aplicação foi calculado pela equação de Christiansen, descrita por Montebeller et al. (2001):

$$
\operatorname{CUC}(\%)=100\left(1-\frac{\sum_{i=1}^{n}\left|X_{i}-\bar{X}\right|}{n \bar{X}}\right)
$$

sendo, $\mathrm{CUC}=$ coeficiente de uniformidade de Christiansen, \%;

$\mathrm{X} \mathrm{i}=$ precipitação observada em cada coletor, $\mathrm{mm} \mathrm{h}^{-1}$;

$\overline{\mathrm{X}}=$ precipitação média dos coletores, $\mathrm{mm} \mathrm{h}^{-1}$;

$\mathrm{n}=$ número de coletores.

As pressões ajustadas para a calibração do simulador foram de 20, 30 e $40 \mathrm{kPa}$. Para cada pressão ajustada, foram simuladas precipitações, em três repetições.

\section{Ensaio de campo}

O estudo de campo foi conduzido no semiárido pernambucano, no município de Pesqueira, na Bacia Representativa do Riacho Mimoso, pertencente à bacia do Rio Ipanema, em sua porção 0 cidental mais a montante. Localiza-se entre $8^{\circ} 34^{\prime} 17^{\prime \prime}$ e $8^{\circ} 18^{\prime} 11^{\prime \prime}$ de Latitude Sul, e $37^{\circ} 1^{\prime} 35^{\prime \prime}$ e $36^{\circ} 47^{\prime}$ $20^{\prime \prime}$ de Longitude O este. A precipitação média anual na região é de $607 \mathrm{~mm}$, com temperatura média de $23^{\circ} \mathrm{C}$ e evapotranspiração de cerca de $2000 \mathrm{~mm}$. A vegetação predominante é a caatinga hipoxerófila, cactáceas e bromeliáceas (Montenegro \& Montenegro, 2006).
Analisando dados de chuva provenientes de pluviógrafos automáticos instalados na bacia, observaram-se intensidades de precipitação anual variando de $26 \mathrm{~mm} \mathrm{~h}^{-1}$ chegando a $170 \mathrm{~mm} \mathrm{~h}^{-1}$ em eventos extremos para um período de aproximadamente 45 minutos, sendo que as chuvas, que ocorrem no período de janeiro a junho, representam $70,35 \%$ da erosividade total anual (Santos et al., 2006) .

0 solo no local do experimento é um $\mathrm{N}$ eossolo Flúvico de textura franco arenosa. As análises textural e química encontram-se na Tabela 1.

Para este estudo, o bico oscilante tipo "Veejet 80-100", de diâmetro interno de $12,7 \mathrm{~mm}$, foi utilizado operando com uma pressão de $30 \mathrm{kPa}$; enquanto o bico "Veejet 80-150", na pressão de 40 $\mathrm{kPa}$. Estas pressões, em campo, devido a influência dos ventos, geraram intensidades próximas a $60 \mathrm{~mm}$ $\mathrm{h}^{-1}$ e $120 \mathrm{~mm} \mathrm{~h}^{-1}$, respectivamente (Tabela 2). A intensidade média das chuvas foi aferida através de 14 pluviômetros distribuídos ao redor da parcela experimental. 0 simulador foi alimentado por uma bomba submersa e caixa de capacidade de $1000 \mathrm{~L}$.

$\mathrm{Na}$ encosta da área experimental, com $6 \%$ de declividade, foram instaladas 15 parcelas de $3 \mathrm{~m}^{2}$ ( $1 \times 3 \mathrm{~m}$ ), delimitadas por chapas de zinco de $20 \mathrm{~cm}$ de altura, cravadas $10 \mathrm{~cm}$ no solo, com a maior dimensão no sentido do declive. Na parte inferior das parcelas foi instalada calha coletora para a amostragem da enxurrada.

Os tratamentos, com três repetições cada, foram: feijão cultivado segundo curvas de nível (N) associado a fileiras de pedra, com aproximadamente $8 \mathrm{~cm}$ de altura, entre as fileiras do feijão; feijão cultivado morro abaixo (MA); feijão cultivado em nível, com cobertura morta (CM), tendo sido utilizada palha de feijão, distribuída uniformemente na parcela; solo descoberto (D); e, finalmente, solo com cobertura vegetal nativa ( $\mathrm{CN}$ ), a qual se encontrava com $100 \%$ de cobertura vegetal. A cultura do feijoeiro (Phaseolus vulgaris L.) estava na fase de crescimento, no $20^{\circ}$ dia, tendo sido cultivado no espaçamento de $0,50 \times 0,20 \mathrm{~m}$

Os testes de chuva simulada tiveram duração de uma hora e vinte minutos, e as coletas foram realizadas a cada 5 minutos, a partir do início do escoamento, com duração de 10 segundos.

\section{Características hidráulicas do escoamento}

A velocidade do escoamento superficial foi estimada com auxílio do corante azul de metileno, considerando pontos fixos na parcela, distanciados de $2 \mathrm{~m}$. Este procedimento foi realizado a intervalos 
Erosão Hídrica e Perda de Carbono Orgânico em Diferentes Tipos de Cobertura do Solo no Semi-Árido, em Condições de Chuva Simulada

Tabela 1 - Características textural e química do solo no local do experimento

\begin{tabular}{|c|c|c|c|c|c|c|c|c|c|c|c|}
\hline $\begin{array}{l}\text { Comp } \\
\text { trica }\end{array}$ & sição & granulor & & Caracter & sticas & juímic & & & & & \\
\hline (\%) & & & $\mathrm{pH}$ & $P$ & $\mathrm{~K}$ & $\mathrm{Ca}$ & $\mathrm{Mg}$ & $\mathrm{Na}$ & $\mathrm{Al}$ & $(\mathrm{H}+\mathrm{Al})$ & $\mathrm{CO}$ \\
\hline Areia & Silte & Argila & $\left(\mathrm{H}_{2} \mathrm{O}\right)$ & $\mathrm{mg} \mathrm{dm}^{-3}$ & $\mathrm{cmol}$ & $\mathrm{dm}^{-3}$ & & & & & $\mathrm{~g} \mathrm{~kg}^{-}$ \\
\hline 63 & 15 & 22 & 5,6 & 2,75 & 0,12 & 1,98 & 0,33 & 0,06 & 0,07 & 0 & 7,93 \\
\hline
\end{tabular}

Tabela 2 - Intensidade de precipitação média $\left(\mathrm{mm} \mathrm{h}^{-1}\right)$ gerada para cada tratamento avaliado

\begin{tabular}{lll}
\hline \multirow{2}{*}{ Tratamentos } & \multicolumn{2}{l}{ Pressão aplicada nos bicos $(\mathrm{kPa})$} \\
\cline { 2 - 3 } & 30 & 40 \\
\hline Descoberta & $59,84 \mathrm{a}$ & $120,55 \mathrm{a}$ \\
Morro abaixo & $59,73 \mathrm{a}$ & $119,97 \mathrm{a}$ \\
Nível & $59,73 \mathrm{a}$ & $119,78 \mathrm{a}$ \\
$\begin{array}{l}\text { Cobertura } \\
\text { ta mor- }\end{array}$ & $59,31 \mathrm{a}$ & $120.56 \mathrm{a}$ \\
$\begin{array}{l}\text { Cobertura nati- } \\
\text { va }\end{array}$ & $59,91 \mathrm{a}$ & $120,74 \mathrm{a}$ \\
\hline
\end{tabular}

Médias seguidas de letras minúsculas na mesma coluna, não diferem entre si, ao nível de $5 \%$ de significância, pelo teste de Tukey. Média de três repetições.

de 5 minutos, a partir da formação e deslocamento da lâmina de escoamento.

Os valores da velocidade superficial do escoamento foram multiplicados por um fator de correção ( $\alpha=2 / 3)$, para obtenção da velocidade média do escoamento, em $\mathrm{m} \mathrm{s}^{-1}$, conforme Farenhorst \& Bryan (1995) e Katz et al. (1995).

A altura da lâmina do escoamento (h) foi então determinada como:

$\mathrm{h}=\frac{\mathrm{q}}{\mathrm{V}}$

onde $\mathrm{h}=$ altura da lâmina de escoamento $(\mathrm{m}), \mathrm{q}=$ descarga líquida total por unidade de largura em $\left(m^{2} s^{-1}\right), V=$ velocidade média do escoamento $\left(\mathrm{m} \mathrm{s}^{-1}\right)$. A descarga líquida (q) foi expressa em $\left(m^{2} s^{-1}\right)$, sendo determinada a partir das coletas de enxurrada na extremidade inferior da calha coletora, a cada 5 minutos.

A viscosidade cinemática da água foi avaliada pela utilização da equação seguinte, segundo Julien (1995), sendo a temperatura $\left({ }^{\circ} \mathrm{C}\right)$ medida por meio de um termômetro, em cada teste:

$$
v=\left(1,14-0,031(\mathrm{~T}-15)+0,00068(\mathrm{~T}-15)^{2}\right) \times 10^{-6}
$$

onde $v=$ viscosidade cinemática da água $\left(\mathrm{m}^{2} \mathrm{~s}^{-1}\right), \mathrm{T}=$ temperatura da água em ${ }^{\circ} \mathrm{C}$.

O número de Reynolds (Re) foi obtido, segundo Simons (1992), por:

$\mathrm{Re}=\frac{\mathrm{Vh}}{v}$

onde $\operatorname{Re}=$ número de Reynolds, adimensional, $v=$ viscosidade cinemática da água $\left(\mathrm{m}^{2} \mathrm{~s}^{-1}\right)$.

0 número de Froude ( $\mathrm{Fr}$ ), de forma clássica pela equação 5:

$\mathrm{Fr}=\frac{\mathrm{V}}{\sqrt{\mathrm{gh}}}$

onde $\mathrm{Fr}=$ número de Froude, adimensional, $\mathrm{g}=$ aceleração da gravidade $\left(\mathrm{m} \mathrm{s}^{-2}\right)$.

A partir dos números de Reynolds e Froude, classificou-se o regime dos escoamentos gerados a partir das chuvas simuladas.

A rugosidade foi determinada pelo coeficiente de Manning $(n)$, conforme Braida \& Cassol (1999):

$\mathrm{n}=\frac{\mathrm{h}^{\frac{5}{3}} \mathrm{~S}^{\frac{1}{2}}}{\mathrm{q}}$ 
onde $\mathrm{n}$ é coeficiente de rugosidade de Manning ( $\mathrm{s}$ $\left.\mathrm{m}^{-1 / 3}\right)$; h é altura da lâmina de escoamento $(\mathrm{m})$; q é a descarga líquida $\left(\mathrm{m}^{2} \mathrm{~s}^{-1}\right) ; \mathrm{S}$ é o declive da parcela $\left(\mathrm{m} \mathrm{m}^{-1}\right)$.

A taxa de infiltração foi, então, obtida por balanço, considerando a diferença entre a intensidade de precipitação e a taxa de escoamento superficial resultante (Brandão et al., 2006).

Taxas de desagregação e perdas de solo

As taxas de perda de solo e a concentração de sedimentos foram estimadas pela pesagem do material coletado. Os potes, após pesagem, foram deixados em repouso e após 24 horas, o sobrenadante foi succionado e os potes levados para secagem em estufa a $65^{\circ} \mathrm{C}$, sendo em seguida pesados com o solo (Cogo, 1978). A relação entre a massa de solo seco e a massa de mistura água-sedimento expressa a concentração de sedimentos em $\left(\mathrm{kg} \mathrm{L}^{-1}\right)$. As taxas de desagregação do solo (D) foram determinadas como:

$\mathrm{D}=\frac{\mathrm{Mss}}{\mathrm{ADc}}$

onde: $D=$ taxa de desagregação do solo $\left(\mathrm{kg} \mathrm{m}^{-2} \mathrm{~s}^{-1}\right)$, Mss= massa do solo seco desagregado $(\mathrm{kg}), \mathrm{A}=$ área da parcela $\left(\mathrm{m}^{2}\right)$ e $\mathrm{Dc}=$ duração da coleta em (s). Finalmente, as perdas de solo podem ser expressas por:

$\mathrm{Ps}=\frac{\sum(\mathrm{Q} C \mathrm{t} t)}{\mathrm{A}}$

onde: $\mathrm{Ps}=$ perdas de solo $\left(\mathrm{kg} \cdot \mathrm{m}^{-2}\right) ; \mathrm{Q}=$ vazão $\left(\mathrm{L} \cdot \mathrm{s}^{-1}\right)$; $\mathrm{Cs}=$ concentração de sedimento $\left(\mathrm{kg} \mathrm{L}^{-1}\right) ; \mathrm{t}=$ intervalo entre as coletas ( $300 \mathrm{~s}$ ) e $A=$ área da parcela $\left(\mathrm{m}^{2}\right)$.

Avaliação da porcentagem de cobertura vegetal do solo pelo método fotográfico

A porcentagem de cobertura do solo foi determinada através do método de $M$ annering, de larga aplicação (Bezerra \& Cantalice, 2006; Rizzard \& Fleck, 2004; Bertol, 2005), que utiliza a projeção fotográfica de uma moldura com a cobertura vegetal da área sobre um quadro padrão, apresentado na Figura 1. Com a soma da contagem das interseções, com os pontos de cobertura vegetal da superfície (copa/ resíduo) projetados, tem-se a porcentagem total de cobertura vegetal, sendo que cada ponto de interseção representa $2 \%$ da área total. Na Figura 2 estão representados os tratamentos adotados neste estudo, podendo-se notar o quadro de madeira delimitador.

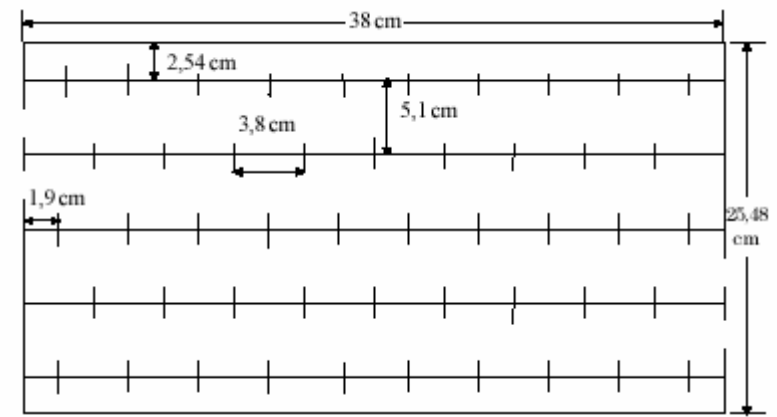

Figura 1 - Q uadro padrão utilizado para determinar a porcentagem de cobertura do solo, com a projeção fotográfica.

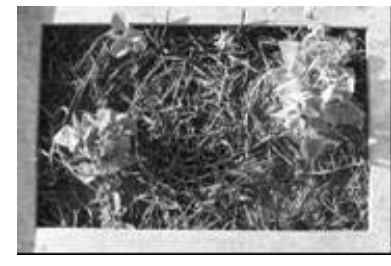

(a)

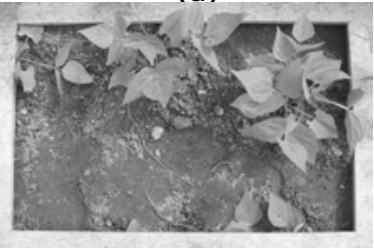

(c)

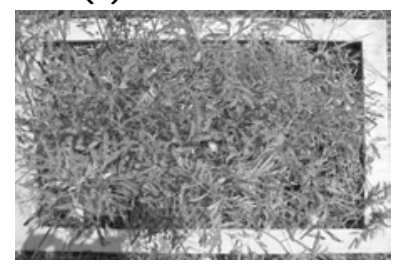

(e)

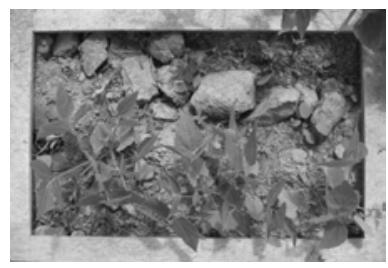

(b)

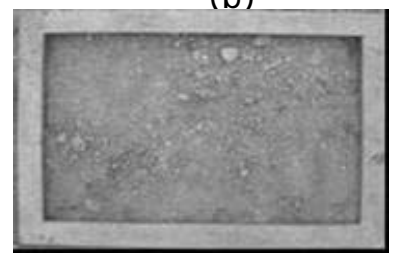

(d)
Figura 2 - Representação da cobertura vegetal nos tratamentos: (a) feijão cultivado em nível + cobertura morta,

(b) feijão cultivado em nível + microbarramentos, (c)

feijão cultivado morro abaixo, (d) solo descoberto e (e) cobertura nativa. 
Erosão Hídrica e Perda de Carbono Orgânico em Diferentes Tipos de Cobertura do Solo no Semi-Árido, em Condições de Chuva Simulada

\section{Perda de Carbono orgânico}

Foram coletadas amostras do solo após cada teste de chuva simulada, na profundidade de 0-20 $\mathrm{cm}$, em uma locação em cada parcela, nas quais foi determinado o teor de CO (Bertol, 2004).

Após secagem do material coletado, proveniente da enxurrada, o sedimento foi pesado e armazenado para posterior análise química. A quantidade de carbono dos sedimentos $\left(\mathrm{kg} \mathrm{kg}^{-1}\right)$, de cada parcela, foi multiplicada pela perda total de solo carreado pela erosão ( $\left.\mathrm{kg} \mathrm{ha}^{-1}\right)$, fornecendo, assim, uma estimativa do total de carbono perdido, em kg ha-1 (Izidório et al., 2005).

Os teores de carbono orgânico, tanto no solo, quanto no sedimento foram determinados adotando-se metodologia da EMBRAPA (1997), onde utilizou-se como agente oxidante o dicromato de potássio em meio sulfúrico, sendo a reação acelerada por aquecimento. Como titulante foi utilizado o sulfato ferroso.

\section{Delineamento experimental}

0 delineamento experimental foi 0 inteiramente casualizado em parcelas subdivididas, sendo a subparcela a intensidade de precipitação aplicada. 0 delineamento foi composto por cinco tratamentos e três repetições, resultando em um total de 15 ensaios de chuva simulada. A análise estatística foi realizada utilizando-se o "software" SAS- Statistical Analitical System (SAS Institute, 1998). Para comparação entre as médias de tratamentos, adotouse o teste de Tukey ao nível de significância de 5\%.

\section{RESULTADOS E DISCUSSÃO}

Hidráulica do simulador de chuvas

Valores de intensidade de precipitação, e os coeficientes de uniformidade para os dois tipos de bicos utilizados encontram-se na Tabela 3. Cassol \& Guerra (1978) encontraram coeficientes de uniformidade da ordem de $91,6 \%$ para o bico 80-100, operando na pressão de $42,18 \mathrm{kPa}$. Alves Sobrinho et al. (2002) obtiveram coeficientes entre 83 e $85,8 \%$ para uma pressão de $32,7 \mathrm{kPa}$, para o mesmo bico; Para o bico 80-150, estes autores encontraram valores de coeficientes que variaram entre 82 e $87,1 \%$, para uma pressão de $27,6 \mathrm{kPa}$. Em campo, esses coeficientes ficaram entre 85,57 e 85,81\%, para o bico Veejet "80-100" e entre 82,65 e 84,56\%, para o bico Veejet "80-150". Com coeficientes superiores a $75 \%$, pode-se considerar uma adequada uniformidade de chuva.

Podem ser adotados outros valores de intensidade com o aumento da pressão, tomando-se 0 cuidado para que a mesma não ultrapasse $70 \mathrm{kPa}$, no bico 80-100. Segundo Meyer \& Harmon (1979), acima desta pressão, este bico provoca uma deformação do tamanho das gotas, alterando a velocidade de queda e a energia cinética de impacto da gota. A relação entre as intensidades e as pressões utilizadas tem comportamento linear, com coeficiente de determinação de 0,94 e 0,97 para os bicos 80-100 e 80-150, respectivamente.

\section{Hidráulica do escoamento}

Devido à alta percentagem de cobertura vegetal existente nos tratamentos $\mathrm{CN}$ e CM, não foi possível observar o escoamento superficial direto nos mesmos, impossibilitando se obter as características hidráulicas, exceto quando se aplicou a intensidade de precipitação de $120 \mathrm{~mm} \mathrm{~h}^{-1}$, na condição de cobertura natural.

O bserva-se na Tabela 4, que os valores adimensionais de Reynolds e de Froude se situam nos intervalos de $\mathrm{Re}<500$ e $\mathrm{Fr}<1$, e os valores de descarga líquida são de ordem de grandeza de $10^{-5} \mathrm{~m}^{2} \mathrm{~s}$ 1 , enquanto a altura de lâmina de $10^{-3} \mathrm{~m}$. Desse modo, o regime de escoamento pode ser classificado como laminar lento, mesmo com o aumento da intensidade aplicada, sugerindo que ocorreu escoamento característico de erosão entressulcos. Estes valores estão de acordo com os encontrados por Bezerra \& Cantalice (2006), em área de cultivo de cana-de-açúcar sob o escoamento superficial na erosão entressulcos, em um Argissolo VermelhoAmarelo, utilizando simulador de chuvas com intensidade de precipitação de $100 \mathrm{~mm} \mathrm{~h}^{-1}$.

Embora os sistemas de manejo tenham apresentado descargas líquidas semelhantes, no cultivo em nível e com cobertura morta, o número de Froude foi baixo devido à presença das barreiras físicas, que impediram o livre escoamento. A velocidade de escoamento foi reduzida em $28 \%$ no cultivo em nível com barreira, em relação tanto à condição morro abaixo quanto à descoberta, para a aplicação de $60 \mathrm{~mm} \mathrm{~h}^{-1}$. Para a maior intensidade ( $120 \mathrm{~mm} \mathrm{~h}$ $\left.{ }^{1}\right)$, por sua vez, as reduções foram de 44,4 e 17\%, quando se comparam os tratamentos nível com barreiras e morro abaixo, e nível com barreiras e parcela descoberta, respectivamente. Fica evidenciada, assim, a relevância do plantio em curvas de nível e utilizando barreiras em pedras na redução da velocidade de escoamento e, assim, no controle das 
Tabela 3 - Resultados da calibração do simulador de chuvas com dois tipos de bicos aspersores Veejet "80-100" e "80-150"

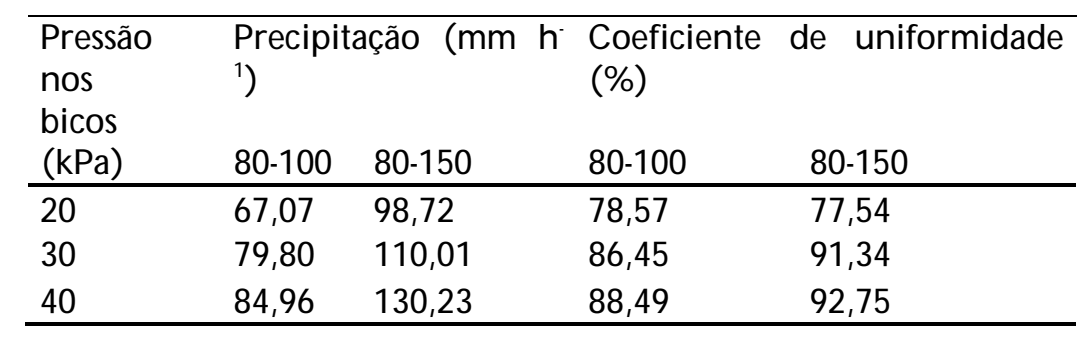

perdas de solo e indução do processo de infiltração. U ma vez que a presença de barreiras diminui a velocidade de escoamento superficial da água, e assim sua capacidade de transportar sedimentos.

Quando se adotou a intensidade de $120 \mathrm{~mm}$ $\mathrm{h}^{-1}$, a velocidade de escoamento do tratamento de cultivo em curvas de nível com barramentos não apresentou diferença significativa em relação à parcela com cobertura natural. A condição de solo descoberto apresentou velocidade de escoamento igual a $0,042 \mathrm{~m} \mathrm{~s}^{-1}$, não diferindo estatisticamente da condição morro abaixo. Resultados semelhantes foram encontrados por Pan \& Shangguan (2006) avaliando as características hidráulicas do escoamento superficial da água, em parcelas desmatada e coberta, sob condições de chuva simulada em laboratório, com intensidade de $100 \mathrm{~mm} \mathrm{~h}^{-1}$, estes autores encontraram velocidade de escoamento superficial igual a $0,052 \mathrm{~m} \mathrm{~s}^{-1}$ para a parcela sem cobertura vegetal. Tais resultados reforçam as hipóteses apresentadas por Padilha (2000), no que se refere à relevância de barreiras em pedra para controle das perdas de solo.

A partir da Tabela 5 pode-se verificar que 0 tratamento de cultivo em nível apresentou uma maior altura de lâmina, para a intensidade de 60 $\mathrm{mm} \mathrm{h}^{-1}$. A cobertura promovida pela condição natural proporcionou a mais elevada altura de lâmina, com valor de $0,0221 \mathrm{~m}$, correspondendo à alta resistência ao escoamento, fato confirmado pelo maior valor da rugosidade, $0,74 \mathrm{~s} \mathrm{~m}^{-1 / 3}$, enquanto que para a condição de solo descoberto este valor foi igual a $0,055 \mathrm{~s} \mathrm{~m}^{-1 / 3}$. Este resultado está de acordo com 0 comportamento observado por Cassol et al. (2004), que avaliaram as condições hidráulicas e as relações de desagregação do solo e de resistência ao escoamento com a presença de resíduos vegetais na erosão em entressulcos, em um Argissolo Vermelho distrófico típico, em parcelas com $0,10 \mathrm{~m} \mathrm{~m}^{-1}$ de declive, e sob chuva simulada. Esses autores encontraram valores de rugosidade superficial de 0,043 e $0,522 \mathrm{~s} \mathrm{~m}^{-1 / 3}$ para as condições de solo descoberto e com adição de $0,80 \mathrm{~kg} \mathrm{~m}^{-2}$ de palha, respectivamen- te. Estando bem próximos aos valores encontrados neste estudo para a mesma condição.

Desagregação, perda de solo e cobertura vegetal

O bserva-se na Tabela 6 que houve diferença estatística entre as médias dos tratamentos, onde as condições morro abaixo e descoberta apresentaram os maiores valores de desagregação, com diferença estatística em relação às demais condições, para as duas intensidades. Houve redução de 93,39 e $51,11 \%$ para $(C M)$ e $(N)$, respectivamente, em relação à condição (MA), na intensidade de $60 \mathrm{~mm} \mathrm{~h}^{-1}$. Com o aumento da intensidade de precipitação, a condição $(N)$ reduziu as taxas de desagregação em $19,46 \%$ em relação à condição (MA). A condição CN apresentou redução de 94,74 e $84,62 \%$ em relação à parcela desmatada, para as intensidades de 60 e $120 \mathrm{~mm} \mathrm{~h}^{-1}$, respectivamente, ressaltando a relevância da caatinga na conservação do solo no semiárido. Estas reduções podem ser explicadas pelo fato de que os principais agentes externos responsáveis pelo desprendimento dos agregados em condições agrícolas são aqueles associados ao impacto das gotas de chuva e ao escoamento superficial. Como nos demais tratamentos havia barreiras (pedras e cobertura vegetal) que dificultavam o escoamento, ocorreu menor desprendimento e arraste de partículas sólidas, observando-se, assim, a eficácia da cobertura morta na redução das taxas erosivas. Cassol et al. (2004) encontraram reduções de $90,62 \%$ na taxa de desagregação com $100 \%$ de cobertura do solo por resíduos da cultura da soja.

Conseqüentemente, com relação às perdas de solo, observa-se que há diferença significativa entre as médias dos tratamentos. Observa-se uma redução de $61,76 \% ; 83,11 \%$ e de $89,68 \%$ nas perdas de solo para a situação (CM) em relação às condições (N), (MA) e (D) respectivamente, para a intensidade de $60 \mathrm{~mm} \mathrm{~h}^{-1}$. Com base nestes resultados, verifica-se que a condição de cobertura natural (CN) é a que oferece a maior proteção ao solo, co 
Erosão Hídrica e Perda de Carbono Orgânico em Diferentes Tipos de Cobertura do Solo no Semi-Árido, em Condições de Chuva Simulada

Tabela 4 - Características hidráulicas do escoamento (q-descarga líquida, Re-número e Reynolds, Fr-número de Froude e V-velocidade de escoamento superficial), para as condições de cultivo do feijoeiro

\begin{tabular}{lllllllll}
\hline \multicolumn{7}{l}{ Intensidade de precipitação $\left(\mathrm{mm} \mathrm{h}^{-1}\right)$} \\
\cline { 2 - 8 } & 60 & 120 & 60 & 120 & 60 & 120 & 60 & 120 \\
\hline Tratamentos & $\mathrm{q}\left(\mathrm{m}^{2} \mathrm{~s}^{-1}\right)$ & & $\mathrm{Re}$ & & $\mathrm{Fr}$ & & $\mathrm{V}\left(\mathrm{m} \mathrm{s}^{-1}\right)$ & \\
\hline Descoberta & $2,91 \times 10^{-5} \mathrm{a}$ & $6,28 \times 10^{-5} \mathrm{~b}$ & $25,05 \mathrm{a}$ & $49,75 \mathrm{~b}$ & $0,26 \mathrm{~b}$ & $0,40 \mathrm{a}$ & $0,025 \mathrm{aB}$ & $0,042 \mathrm{aA}$ \\
Morro abaixo & $3,78 \times 10^{-5} \mathrm{a}$ & $5,41 \times 10^{-5} \mathrm{~b}$ & $21,49 \mathrm{a}$ & $138,25 \mathrm{ab}$ & $0,28 \mathrm{a}$ & $0,44 \mathrm{a}$ & $0,025 \mathrm{aB}$ & $0,063 \mathrm{aA}$ \\
& & & & & & & & 0,035 \\
Nível & $2,25 \times 10^{-5} \mathrm{a}$ & $7,29 \times 10^{-5} \mathrm{~b}$ & $23,74 \mathrm{a}$ & $87,69 \mathrm{ab}$ & $0,16 \mathrm{~b}$ & $0,23 \mathrm{~b}$ & $0,018 \mathrm{bA}$ & $\mathrm{bA}$ \\
Cobertura & & & & & & & & \\
nativa & - & $5,73 \times 10^{-4} \mathrm{a}$ & - & $39 \mathrm{~b}$ & - & $0,25 \mathrm{~b}$ & - & $0,027 \mathrm{~b}$ \\
CV $(\%)$ & 12,12 & & 9,62 & & 15,73 & & 7,35 & \\
\hline
\end{tabular}

Médias seguidas de letras minúsculas na mesma coluna e de letras maiúsculas na mesma linha, não diferem entre si, ao nível de $5 \%$ de significância, pelo teste de Tukey. Média de três repetições. CV- coeficiente de variação

Tabela 5 - Rugosidade superficial ( $\mathrm{n}$ ), altura da lâmina de escoamento $(\mathrm{h})$ e viscosidade cinemática $(v)$ para as condições de cultivo do feijoeiro

\begin{tabular}{lllllll}
\hline \multicolumn{7}{c}{ Intensidade de precipitação $\left(\mathrm{mm} \mathrm{h}^{-1}\right)$} \\
\cline { 2 - 6 } & 60 & 120 & 60 & 120 & 60 & 120 \\
\hline Tratamentos & $\mathrm{n}\left(\mathrm{s} \mathrm{m}^{-1 / 3}\right)$ & $\mathrm{h}(\mathrm{m})$ & & $v\left(\mathrm{~m}^{2} \mathrm{~s}^{-1}\right)$ & \\
\hline Descoberta & $0,06 \mathrm{~b}$ & $0,05 \mathrm{c}$ & $0,91 \times 10^{-3} \mathrm{~b}$ & $1,10 \times 10^{-3} \mathrm{c}$ & $9,08 \times 10^{-7} \mathrm{a}$ & $9,26 \times 10^{-7} \mathrm{a}$ \\
Morro abai- & & & & & & \\
xo & $0,11 \mathrm{a}$ & $0,11 \mathrm{~b}$ & $0,79 \times 10^{-3} \mathrm{C}$ & $2,03 \times 10^{-3} \mathrm{~b}$ & $9,19 \times 10^{-7} \mathrm{a}$ & $9,25 \times 10^{-7} \mathrm{a}$ \\
Nível & $0,15 \mathrm{a}$ & $0,13 \mathrm{~b}$ & $1,22 \times 10^{-3} \mathrm{a}$ & $2,28 \times 10^{-3} \mathrm{~b}$ & $9,25 \times 10^{-7} \mathrm{a}$ & $9,10 \times 10^{-7} \mathrm{a}$ \\
Cobertura & & & & & & \\
nativa & - & $0,74 \mathrm{a}$ & - & $2,21 \times 10^{-2} \mathrm{a}$ & - & $9,19 \times 10^{-7} \mathrm{a}$ \\
CV $(\%)$ & 8,76 & & 11,12 & & 1,56 & \\
\hline
\end{tabular}

Médias seguidas de letras minúsculas na mesma coluna não diferem entre si, ao nível de $5 \%$ de significância, pelo teste de Tukey. Média de três repetições. $\mathrm{CV}$ - coeficiente de variação; $\mathrm{CN}$ - cobertura vegetal nativa

mo esperado, associada a uma baixa perda de solo $\left(4 \times 10^{-3} \mathrm{~kg} \mathrm{~m}^{-2}\right)$. Para este experimento, o cultivo em nível (N) permitiu uma redução de $55,84 \%$ em relação ao cultivo morro abaixo (MA). Redução de $53,4 \%$ nas perdas de solo também foi encontrada por Albuquerque et al. (2002), para o cultivo da palma em nível em relação ao em desnível, ressaltando, portanto, a eficiência deste instrumento simples no controle da erosão hídrica. Carvalho et al. (2003) encontraram uma redução de $81,1 \%$ na perda de solo com a presença da cobertura morta em relação àquela sem cobertura, sob condição de chuva simulada, com intensidade de precipitação de 50 $\mathrm{mm} \mathrm{h}^{-1}$, e em um Argissolo Vermelho-Amarelo.

0 aumento da taxa de precipitação resultou em aumentos nas perdas de solo para todas as condições, porém com aumento significativo apenas para a condição de solo descoberto. Observou-se uma redução de 32,06\% para a condição (N) em relação à (MA), e de $82,29 \%$ para a condição (CN) em relação à (D). Tejada \& Gonzales (2006), estudando o efeito do incremento de matéria orgânica em um típico Neossolo Flúvico com $2 \%$ de declive, encontraram incremento nas perdas de solo para a intensidade maior de $140 \mathrm{~mm} \mathrm{~h}^{-1} \mathrm{em}$ relação à intensidade menor, de $60 \mathrm{~mm} \mathrm{~h}^{-1}$, para todos os tratamentos avaliados. Panachuki et al. (2006) também encontraram aumento nas perdas de solo ao variar a intensidade de precipitação de 40 para $100 \mathrm{~mm} \mathrm{~h}^{-1}$ na chuva simulada, com aumento de aproximadamente 3,8 vezes nas perdas de solo no sistema plantio direto, em um Latossolo Vermelho com $3 \%$ de declividade em Dourados, MS.

As perdas de solo diminuíram exponencialmente com o aumento da cobertura do solo, com valores de coeficiente de determinação de 0,72 e 
T abela 6 - Taxas de desagregação (D), perda de solo observados nos tratamentos avaliados

\begin{tabular}{|c|c|c|c|c|}
\hline & \multicolumn{4}{|c|}{ Intensidade de precipitação $\left(\mathrm{mm} \mathrm{h}^{-1}\right)$} \\
\hline & 60 & 120 & 60 & 120 \\
\hline Tratamentos & $D\left(\mathrm{~kg} \mathrm{~m}^{-2} \mathrm{~s}^{-1}\right)$ & & $\begin{array}{l}\text { Perda de so } \\
{ }^{2} \text { ) }\end{array}$ & $10\left(\mathrm{~kg} \mathrm{~m}^{-}\right.$ \\
\hline Descoberta & $2,65 \times 10^{-5} \mathrm{aB}$ & $6,83 \times 10^{-5} \mathrm{aA}$ & $0,126 \mathrm{aB}$ & $\begin{array}{l}0,384 a A \\
0,131\end{array}$ \\
\hline Morro abaixo & $1,53 \times 10^{-5} \mathrm{abA}$ & $3,70 \times 10^{-5} \mathrm{abA}$ & $\begin{array}{l}0,077 \mathrm{abA} \\
0,034 \quad \mathrm{ab}-\end{array}$ & $\begin{array}{l}\mathrm{bA} \\
0,089\end{array}$ \\
\hline Níve & $7,48 \times 10^{-6} \mathrm{bcB}$ & $2,98 \times 10^{-5} \mathrm{bcA}$ & $\mathrm{CA}$ & $\mathrm{bA}$ \\
\hline Cober & $1,01 \times 10^{-6} \mathrm{~cd}$ & - & $0,013 \mathrm{bc}$ & $\overline{-}, 068$ \\
\hline $\begin{array}{l}\text { Cobertura nativa } \\
\mathrm{CV}(\%)\end{array}$ & $\begin{array}{l}4,93 \times 10^{-7} \mathrm{~dB} \\
19,08\end{array}$ & $1.05 \times 10^{-5} \mathrm{CA}$ & $\begin{array}{l}0,004 \mathrm{cA} \\
25,46\end{array}$ & bA \\
\hline
\end{tabular}

Médias seguidas de letra minúscula na mesma coluna e de letras maiúsculas nas linhas, não diferem entre si pelo teste de Tukey ao nível de $5 \%$ de significância. Média de três repetições. CV- coeficiente de variação

Tabela 7 - Taxa de infiltração básica e escoamento superficial para os tratamentos avaliados

\begin{tabular}{|c|c|c|c|c|}
\hline \multirow[b]{3}{*}{ Tratamentos } & \multicolumn{4}{|c|}{ Intensidade de precipitação $\left(\mathrm{mm} \mathrm{h}^{-1}\right)$} \\
\hline & 60 & 120 & 60 & 120 \\
\hline & $\begin{array}{l}\text { Taxa de in } \\
{ }_{1} \text { ) }\end{array}$ & tração ( $\mathrm{mm} \mathrm{h}^{-}$ & $\begin{array}{l}\text { Escoamento } \\
\left.\mathrm{h}^{-1}\right)\end{array}$ & superficial $(\mathrm{mm}$ \\
\hline Descoberta & $4,91 \mathrm{cB}$ & $30,17 \mathrm{abA}$ & $53,63 \mathrm{aB}$ & $87,62 \mathrm{aA}$ \\
\hline Morro abaixo & $14,32 \mathrm{bcA}$ & $19,30 \mathrm{bA}$ & $46,02 \mathrm{aB}$ & $87,64 \mathrm{aA}$ \\
\hline Nível & $18,91 \mathrm{bB}$ & 44,13 aA & $39,00 \mathrm{aB}$ & $77,39 \mathrm{aA}$ \\
\hline $\begin{array}{l}\text { ta } \\
\text { Cobertura nati- }\end{array}$ & $55,68 \mathrm{aA}$ & - & $4,36 \mathrm{~b}$ & - \\
\hline $\begin{array}{l}\text { va } \\
\text { CV (\%) }\end{array}$ & $\begin{array}{l}54,95 \text { aA } \\
11,75\end{array}$ & $39,81 \mathrm{abA}$ & $\begin{array}{l}1,13 \mathrm{bB} \\
6,39\end{array}$ & $42,85 \mathrm{bA}$ \\
\hline
\end{tabular}

Médias seguidas de letra minúscula na mesma coluna e de letras maiúsculas nas linhas, não diferem entre si pelo teste de Tukey ao nível de $5 \%$ de significância. Média de três repetições. CV- coeficiente de variação

0,96, para as intensidades de 120 e $60 \mathrm{~mm} \mathrm{~h}^{-1}$, respectivamente (Figura 1). Tal redução está relacionada à cobertura vegetal, a qual absorve a energia das gotas de chuva, conforme ressaltado por Leite et al. (2004). A presença da cobertura vegetal evita o impacto das gotas de chuva diretamente sobre a superfície do solo, dissipando a energia cinética e minimizando a perda de solo. Fica, assim, evidente a grande importância da prática conservacionista na redução da erosão no primeiro estágio de desenvolvimento da cultura, quando a mesma não oferece proteção adequada ao solo. Tal proteção é particularmente importante quando o plantio de sequeiro ocorre logo após as primeiras chuvas do ano, época em que ocorrem com freqüência chuvas de alta intensidade no semi-árido. Comportamento semeIhante foi encontrado por Bezerra \& Cantalice (2006), observando diferentes coberturas do solo no cultivo da cana, tendo-se observado redução exponencial nas perdas de solo em função da cobertura vegetal, com coeficiente de determinação igual a 0,79 . Leite et al. (2004) também observaram diminuição exponencial com o aumento da cobertura do solo, proporcionada por resíduos culturais e pelas copas das plantas, no cultivo do feijoeiro, aplicandose chuvas simuladas com intensidade de $64 \mathrm{~mm} \mathrm{~h}^{-1}$, em um Nitossolo Háplico.

Com relação às taxas de infiltração básica e de escoamento superficial (Tabela 7), observa-se que, para a taxa de $60 \mathrm{~mm} \mathrm{~h}^{-1}$, houve diferença significativa entre as médias, com os tratamentos $\mathrm{CM}$ e $\mathrm{CN}$ apresentando as maiores taxas de infiltração de água no solo. Aumentando-se a intensidade de precipitação, observa-se um aumento nessa taxa para as condições descoberta e em nível. As condições CN, CM, N e MA apresentaram reduções de 91,06; 91,18; 
Erosão Hídrica e Perda de Carbono Orgânico em Diferentes Tipos de Cobertura do Solo no Semi-Árido, em Condições de Chuva Simulada

74,03 e de $65,71 \%$ nas taxas de infiltração da água no solo, respectivamente, quando comparada com a condição de solo descoberto, para a intensidade de $60 \mathrm{~mm} \mathrm{~h}^{-1}$.

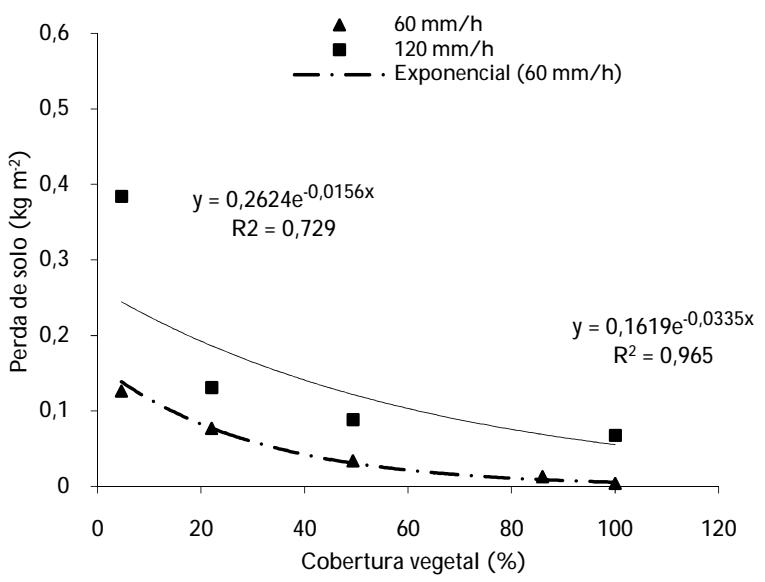

Figura 3 - Relação entre perda de solo e cobertura vegetal para os diferentes tratamentos avaliados

Após 80 minutos de teste, com $60 \mathrm{~mm} \mathrm{~h}^{-1}$, observa-se que houve uma redução de $88,82 \%$ e de $90,52 \%$ no escoamento superficial para o tratamento $(\mathrm{CM})$, em relação aos tratamentos em nível $(\mathrm{N})$ e morro abaixo (MA), respectivamente. Observa-se ainda que 0 aumento da intensidade de precipitação resultou em um aumento no escoamento superficial, com diferença significativa entre a médias para todos os tratamentos. Comparando-se os valores de escoamento superficial para as condições de cobertura nativa e de solo descoberto, a primeira condição reduziu em $97,89 \%$ e $51,09 \%$ o escoamento superficial, para as lâminas de 60 e $120 \mathrm{~mm} \mathrm{~h}^{-1}$, respectivamente. Ressalta-se novamente a relevância da caatinga na redução do escoamento superficial.

Ainda se pode observar a importância da cobertura morta e cobertura nativa nas reduções das taxas de erosão, quando se analisa o tempo para o início do escoamento nos tratamentos estudados. Enquanto que para os tratamentos (MA) e (D) os escoamentos tiveram início após 4,9 e 2,23 minutos do inicio da chuva, respectivamente, nos tratamentos com cobertura morta (CM) e cobertura nativa (CN) os escoamentos só se iniciaram com aproximadamente $27 \mathrm{e}$ 47 minutos de teste, respectivamente, para a intensidade de $60 \mathrm{~mm} \mathrm{~h}^{-1}$. Com o aumento da lâmina, observa-se uma redução do intervalo de tempo para o início do escoamento, com diferença significativa para as condições em nível e cobertura nativa. Panachuki et al. (2006) também encontraram tempo reduzido para o início de escoamento superficial à medida que a intensidade de precipitação foi aumentada. Mello et al. (2003), ao analisarem as perdas de solo e água sob chuva simulada em diferentes sistemas de manejo do solo em um Nitossolo Háplico, obtiveram resultados crescentes em relação ao início do escoamento à medida que se aumentou a cobertura vegetal, com um tempo $94,44 \%$ maior para início da enxurrada para a parcela com semeadura direta em relação à sem cultura.

Tabela 8 - Teores de carbono orgânico na camada de 0-20 $\mathrm{cm}$ de profundidade e no sedimento da erosão, em solo submetido a diferentes sistemas de cultivo do feijoeiro, para a intensidade de $60 \mathrm{~mm} \mathrm{~h}^{-1}$

\begin{tabular}{|c|c|c|c|c|}
\hline \multicolumn{5}{|c|}{ Carbono orgânico } \\
\hline MA & D & $\mathrm{N}$ & CM & $\mathrm{CN}$ \\
\hline \multirow{2}{*}{\multicolumn{5}{|c|}{$\begin{array}{l}\mathrm{kg} \mathrm{kg}^{-1} \\
\text { na camada de } 0-20 \mathrm{~cm} \text { de profundidade do solo }\end{array}$}} \\
\hline & & & & \\
\hline 0,0058 & 0,0050 & 0,0072 & 0,0111 & 0,0176 \\
\hline \multicolumn{5}{|c|}{ no sedimento da erosão } \\
\hline 0,071 & 0,043 & 0,045 & 0,041 & 0,046 \\
\hline \multicolumn{5}{|c|}{$\begin{array}{l}\text { perdido no sedimento da erosão } \\
\mathrm{kg} \mathrm{ha}^{-1}\end{array}$} \\
\hline \multicolumn{5}{|l|}{55,74} \\
\hline a & $55,98 \mathrm{a}$ & $25,03 \mathrm{~b}$ & $5,21 b$ & $0,7 \mathrm{~b}$ \\
\hline
\end{tabular}

Manejo do solo: N: em nível, CM: cobertura morta, MA: morro abaixo, CN: cobertura natural, D: descoberta. Médias seguidas pela mesma letra, nas linhas, não diferem entre si pelo teste de Tukey ao nível de $5 \%$ de significância. Media de três repetições.

\section{Perda de carbono orgânico}

As perdas de carbono orgânico, obtidas no experimento para a intensidade de $60 \mathrm{~mm} \mathrm{~h}^{-1}$, encontram-se na Tabela 8. Considerando-se que as perdas de carbono têm forte correlação com a erosão (Seganfredo et al., 1997), observa-se também aqui que as maiores perdas desse elemento ocorreram nos tratamentos que apresentaram as maiores perdas de solo. Reduções de 98,74 e $90,69 \%$ foram obtidas para os tratamentos (CN) e (CM), respectivamente, em relação ao solo descoberto, explicado pelo o efeito da cobertura na proteção da superfície do solo, contra o transporte de sedimentos ricos em matéria orgânica. Novamente, este resultado é relevante para a sustentabilidade vegetal da caatinga, e 
em concordância com o que preconiza Padilha (2000).

Os teores de carbono orgânico dos sedimentos apresentaram-se maiores em relação ao solo de origem na profundidade de 0 a $20 \mathrm{~cm}$, concordando com Schick et al. (2000), Seganfredo et al. (1997) e Bertol et al. (2004). Isto se deve à textura do material transportado, o qual é mais rico em silte e argila do que o solo de onde se originou o sedimento, uma vez que estas partículas são mais facilmente transportadas e contêm maiores quantidades de nutrientes adsorvidos (Freitas \& Castro, 1983). Outro fator que pode ter levado a este resultado, pode ser explicado pela amostragem realizada na camada de 0-20 cm, que também condiciona um efeito de redução da concentração, uma vez que parte do $\mathrm{C}$ se concentra na superfície.

\section{CONCLUSÕES}

Os bicos aspersores Veejet "80-100" e "80150" apresentaram uma boa uniformidade de distribuição de chuva, com coeficientes de uniformidades superiores a $75 \%$.

Para as condições estudadas, o regime de escoamento apresentado foi o laminar lento. Assim, de acordo com as características hidráulicas observadas, a erosão ocorrida foi entressulcos.

Nos sistemas com adoção da cobertura morta e do cultivo em nível mais barramentos em pedra, as perdas de solo e água mostraram-se consideravelmente reduzidas em relação à prática do cultivo morro abaixo.

Mesmo com o aumento da intensidade de precipitação, a condição de cultivo em nível com os barramentos em pedra apresentou redução significativa, de $28 \%$, na velocidade de escoamento superficial em relação à condição morro abaixo.

As perdas de $\mathrm{CO}$ foram maiores para as condições não conservacionistas do solo do que nos preparos conservacionistas. O sistema de cobertura morta foi eficiente no controle de perda de carbono orgânico e solo, promovendo a manutenção da qualidade do ambiente e conservando os recursos naturais.

As perdas de solo por erosão podem ser reduzidas pela adoção de métodos de preparo e manejo do solo simples, que por sua eficiência e simplicidade representam importantes instrumentos de controle da erosão hídrica.

\section{AGRADECIMENTOS}

Os autores agradecem ao CNPq/ Ct-Hidro pelo apoio financeiro ao desenvolvimento desta pesquisa.

\section{REFERÊNCIAS}

ALBUQUERQUE, A. W.; NETO, F. L.; SRINIVASAN, V. S.; SANTOS, J. R. Manejo da cobertura do solo e de práticas conservacionistas nas perdas de solo e água em Sumé, PB. Revista Brasileira de Engenharia Agrícola e Ambiental, Campina Grande, v.6, n.1, p.136-141, 2002.

ALVES SOBRINHO, T.; FERREIRA, P.A.; PRUSKI, F.F. Desenvolvimento de um infiltrômetro de aspersão portátil. Revista Brasileira de Engenharia Agrícola e Ambiental, v.6, n.2, p.337-344, 2002.

BERTOL, O.J. Contaminação da água de escoamento superficial e da água percolada pelo efeito de adubação mineral e adubação orgânica em sistema de semeadura direta. Tese de Doutorado. Universidade Federal do Paraná. 2005. 209p.

BERTOL, I.; LEITE, D.; GUADAGNIN, J.C. \& RITTER, S.R. Erosão hídrica em um Nitossolo Háplico submetido a diferentes sistemas de manejo sob chuva simulada. II - Perdas de nutrientes e carbono orgânico. Revista Brasileira de Ciência do Solo, v.28, n.6, p.10451054, 2004.

BERTONI, J.; LOMBARDI NETO, F. Conservação do solo. 4.ed. São Paulo: Ícone, 1999.355p.

BEZERRA, S.A.; CANTALICE, J.R.B. Erosão entressulcos em diferentes condições de cobertura do solo, sob o cultivo da cana-de-açúcar. Revista Brasileira de Ciência do Solo, v.30, n.4, p.565-573, 2006.

BRAIDA, J.A.; CASSOL, E.A. Relações de erosão em entressulcos com o tipo e a quantidade de resíduo vegetal na superfície do solo. Revista Brasileira de Ciência do Solo, v.23, n.1, p.711-721, 1999.

BRANDÃO, V.S.; PRUSKI, F.F.; SILVA, D.D. Infiltração da água no solo. 3.ed. Viçosa: Gráfica Universitária, 2006. 120p.

CARVALHO, R.; SILVA, M.L.N.; AVANZI, J.C.; CURI, N.; SOUZA, F.S. Erosão hídrica em Latossolo Vermelho sob diversos sistemas de manejo do cafeeiro no Sul de Minas Gerais. Ciência Agrotécnica, Lavras, v.31, n.6, p.1679-1687, 2007.

CARVALHO, D.F.; MONTEBELLER, C.A.; CRUZ, E.S.; CEDDIA, M.B.; LANA, A.M.Q. Perdas de solo e água em um Argissolo Vermelho-Amarelo, submetido a dife- 
Erosão Hídrica e Perda de Carbono Orgânico em Diferentes Tipos de Cobertura do Solo no Semi-Árido, em Condições de Chuva Simulada

rentes intensidades de chuva simulada. Revista Brasileira de Engenharia Agrícola e Ambiental, Campina Grande, v.6, n.3, p.385-389, 2002

CARVALHO, D. F.; MONTEBELLER, C.A.; CRUZ, E.S.; LANA A.M.Q.; SILVA, W.A. Efeito da Cobertura Morta e do Preparo do terreno nas perdas de Solo e Água em um Argissolo Vermelho-Amarelo. Engenharia na Agricultura. Viçosa, v.11, n.1-4, p. 15-22, 2003.

CASSOL, E.A. \& GUERRA. Calibração do primeiro simulador de chuvas de braços rotativos do Estado do Rio Grande do Sul. Passo Fundo, EMBRAPA. 1978. 481p.

CASSOL, E. A.; LIMA, V. S. Erosão em entressulcos sob diferentes tipos de preparo e manejo do solo. Pesquisa agropecuária brasileira, Brasília, v. 38, n. 1, p. 117-124, 2003.

CASSOL, E.A.; CANTALICE, J.R.B.; REICHERT, J.M.; MONDARDO, A. Escoamento superficial e desagregação do solo em entressulcos em solo franco-argiloarenoso com resíduos vegetais. Pesquisa Agropecuária Brasileira, v.39, n.7, p.685-690, 2004.

COGO, N.P. Uma contribuição à metodologia de estudo das perdas de erosão em condições de chuva natural. I. Sugestões gerais, medição dos volumes, amostragem e quantificação de solo e água da enxurrada. 1a aproximação. In.: ENCONTRO NACIONAL DE PESQUISA SOBRE CONSERVAÇÃO DO SOLO, 2. Passo Fundo, 1978. Anais. Passo Fundo, Empresa Brasileira de Pesquisa Agropecuária, 1978. p.75-98.

EMBRAPA. Centro Nacional de Pesquisa de Solos (Rio de Janeiro, RJ). Manual de métodos de análise do solo. Rio de Janeiro, 1997. 212p.

FARENHORST, A.; BRYAN, R. B. Particle size distribution of sediment transported by shallow flow. Catena., v.25, n.2, p. 47-62, 1995.

FREITAS, P.L.; CASTRO, A.F. Estimativas das perdas de solo e nutrientes por erosão no Estado do Paraná. Boletim Informativo, SBCS, v.8, p.43-52, 1983.

IZIDORIO, R.; MARTINS FILHO, M.V., MARQUES JÚNIOR, J.; SOUZA, Z.M.; PEREIRA, G.T. Perdas de nutrientes por erosão e sua distribuição espacial em área sob cana-de-açúcar. Engenharia Agrícola, Jaboticabal, v.25, n.3, p.660-670, 2005.

JULIEN, P.Y. Erosion and sedimentation. Melbourne: Cambridge University Press, 1995. 280p.

KATZ, D. M.; WATTS, F.J.; BURROUGHS, E. R. Effects of surface roughness and rainfall impact on overland flow. Journal of the Hydraulics Division, ASCE, New York, v. 121, n.1, p. 547-553, 1995.

LEITE, D.; BERTOL, I.; GUADAGNIN, J.C. Erosão hídrica em um Nitossolo Háplico submetido a diferentes sistemas de manejo sob chuva simulada. I - Perdas de solo e água. Revista Brasileira de Ciência do Solo, v.28, n.6, p.1033-1044, 2004.
MELLO, E. L.; BERTOL, I.; ZAPAROLLI, A. L. V. \& CARRAFA, M. R. Perdas de solo e água em diferentes sistemas de manejo de um Nitossolo Háplico submetido à chuva simulada. Revista Brasileira de Ciência do Solo, v. 27, n.5, p.901-909, 2003.

MEYER, L.D.; HARMON, W.C. Multiple intensity rainfall simulator for erosion research on row sideslopes. Transactions of the ASAE, St. Joseph, v.22, n.1, p.100103, 1979.

MONTEBELLER, C. A.; CARVALHO, D. F.; SOBRINHO, T. A.; NUNES, A. C. S.; RUBIO, E. Avaliação hidráulica de um simulador de chuvas pendular. Revista Brasileira de Engenharia Agrícola Ambiental, Campina Grande, v.5, n.1, p.1-5, 2001.

MONTENEGRO, A.A.A.; MONTENEGRO, S.M.G.L. Variabilidade espacial de classes de textura, salinidade e condutividade hidráulica de solos em planície aluvial. Revista Brasileira de Engenharia Agrícola, Campina Grande, v.10, n.1, p.30-37, 2006.

PADILHA, J. A. "Base Zero Ano 2000: mudança de paradigma na produção agroambiental nos trópicos secos". In: Pedro Sisnado Leite et al. (orgs.). Reforma agrária e desenvolvimento sustentável. Brasília, Ministério do Desenvolvimento Agrário/ NEAD. 2000.

PAN, C.; SHANGGUAN, Z. Runoff hydraulic characteristics and sediment generation in sloped grassplots under simulated rainfall conditions. Journal of Hidrology, v.331, n.2, p.178-185.

PANACHUKI, E.; ALVES SOBRINHO, T.; VITORINO, A.C.T.; CARVALHO, D.F.; URCHEI, M.A. Avaliação da infiltração de água no solo, em sistema de integração agricultura-pecuária, com uso de infiltrômetro de aspersão portátil. Maringá, v.28, n.1, p.129-137, 2006.

RIZZARDI, M.A.; FLECK, N.G. Métodos de quantificação da cobertura foliar da infestação de plantas daninhas e da cultura da soja. Ciência Rural,v.34, n.1, p.13-18, 2004.

SANTOS, C.A.G.; SUZUKI, K.; WATANABE, M.; SRINIVASAN, V. Influência do tipo da cobertura vegetal sobre a erosão no semi-árido paraibano. Revista Brasileira de Engenharia Agrícola e Ambiental, v.4, n.1, p.9296, 2000.

SANTOS, T.E.M.; SILVA, J.R.L.; ANDRADE, T.S.; MONTENEGRO, A.A.A.; SILVA JÚNIOR, V.P.; SANTOS, E.S. Índice de erosividade $\left(E I_{30}\right)$ das chuvas para a bacia experimental do Jatobá, no semi-árido pernambucano. In: Anais do VIII Simpósio de Recursos Hídricos do Nordeste. Gravatá, Anais..., 2006.

SAS Institute, Inc. The SAS System for windows: Release versão 6.8, Cary, 1998. CD-ROM.

SCHICK, J.; BERTOL, I.; BATISTELA, O. \& BALBINOT JR., A.A. Erosão hídrica em Cambissolo Húmico alumínico submetido a diferentes sistemas de preparo e cul- 
tivo do solo: I. Perdas de solo e água. Revista Brasileira de Ciência do Solo, v.24, n.2, p.427-436, 2000.

SEGANFREDO, M.L.; ELTZ, F.L.F.; BRUM, A.C.R. Perdas de solo, água e nutrientes por erosão em sistemas de culturas em plantio direto. Revista Brasileira de Ciência do Solo, v.21, n.2, p.287-291, 1997.

SILVA, A.M.; SCHULZ, H.E. Estimativa do fator "C" da EUPS para cobertura morta de resíduos vegetais de origem urbana para as condições de São Carlos (SP, Brasil). Interciência, v.26, n.12, p.615-618, 2001

SILVEIRA, R.C.; SALVADOR, N. Uso de um simulador de chuvas no estudo de perdas de solo e água em parcelas com resíduos culturais de milho. Ciência Agrotécnica, v.1, n.3, p. 718-729, 2000.

SIMONS, D.B.; SENTURK,F. Sediment Transport Technology: water and sediment dynamics. In: Water Resources Publications. Colorado: s.n., 1992.

SORATTO, R.P.; CRUSCIOL, C.A.C.; SILVA, L.M.; LEMOS, L.B. Aplicação tardia de nitrogênio no feijoeiro em sistema de plantio direto. Bragantia, v.64, n.2, p.211218, 2005

TEJADA, M.; GONZALEZ, J.L. The relationships between erodibility and erosion in a soil treated with two organic amendments. Soil \& Tillage Research, v.91, p.186-198, 2006.

VIEIRA, M. J.; COGO, N. P.; CASSOL, E. A. Perdas por erosão em diferentes sistemas de preparo do solo para a cultura da soja (Glycine max. (L.) Merril) em condições de chuva simulada. Revista Brasileira de Ciência do Solo, v.2, n.3, p.209-214, 1978.

Water Erosion and Loss of Organic Carbon in Diferent Typis of Soil Cover in the Semi-Arid, Under Simulated Rain Conditions

\section{ABST RACT}

Considering the low water availability in the semiarid region, and the low levels of agricultural management in this region, this work aimed to evaluate the performance of soil and water conservation practices in the semi-arid area of Pernambuco State. The study was developed in the M imoso river Representative Basin, where soil, water and organic carbon losses in the transported sediment were estimated, considering two simulated rainfall intensities, 60 and $120 \mathrm{~mm} \mathrm{~h}^{-1}$, with an 80 minute duration. The experiment was conducted in a Fluvic $\mathrm{Neossol}$, with a slope of $0,061 \mathrm{~m} \mathrm{~m}^{-1}$. The treatments performed in $3 \mathrm{~m} \times 1 \mathrm{~m}$ erosion plots, were: bean cultivated in level $(\mathrm{N})$ with rock barriers between each planted row. With a $0.5 \mathrm{~m}$ spacing; bean planted downslope (DS); bean cropped in level with mulching cover (MC), using bean straws; cleared bare soil (CB) and natural covering (CN). The bean crop (Phaseolus vulgaris L.) was in the initial growing stage, a critical stage, in terms of leaf area in dex cover. The results demonstrated that the natural condition offered the higher soil protection, associated with a soil loss of $4,01 \times 10^{-3} \mathrm{~kg} \mathrm{~m}^{-2}$ and of $6,8 \times 10^{-2} \mathrm{~kg} \mathrm{~m}^{-2}$, for the 60 and $120 \mathrm{~mm} / \mathrm{h}$ intensities, respectively. The mulching cover was closest to this condition. Increasing the rainfall intensity resulted in increased soil and water losses, with higher losses in the following order: cleared bare soil, bean cropped downslope, bean cultivated in level with rock barriers between each planted row. Organic carbon losses were significantly higher for the non-conservation soil practices condition..

Keywords: soil conservation practices; soil losses; sediments; rainfall simulator. 